\title{
All Precordial Electrodes Are Disconnected by ECG Finding
}

National Cancer Institute

\section{Source}

National Cancer Institute. All Precordial Electrodes Are Disconnected by ECG Finding. NCI Thesaurus. Code C114159.

An electrocardiog raphic recording in which all precordial electrodes are disconnected resulting in missing waveforms (flat line) of all leads V1 - V6. (CDISC) 